\title{
The effect of hypertension on aortic pulse wave velocity in type-1 diabetes mellitus patients: assessment with MRI
}

\author{
A. Brandts - S. G. C. van Elderen $\cdot$ J. T. Tamsma $\cdot$ \\ J. W. A. Smit • L. J. M. Kroft • H. J. Lamb • \\ R. W. van der Meer $\cdot$ J. J. M. Westenberg $\cdot$ A. de Roos
}

Received: 14 November 2010/Accepted: 26 February 2011/Published online: 11 March 2011

(C) The Author(s) 2011. This article is published with open access at Springerlink.com

\begin{abstract}
To investigate in type-1 diabetes mellitus (DM1) patients the role of hypertension and of DM1 itself on aortic stiffness by using magnetic resonance imaging (MRI). Consecutive patients from the diabetes and hypertension outpatient clinic and healthy volunteers were included in our study. Subjects were divided into four groups: 32 healthy volunteers (mean age: $54.5 \pm 6.8$ years), 20 DM1 patients (mean age: $48.3 \pm 5.9$ years), 31 hypertensive patients (mean age: $59.9 \pm 7.2$ years) and 28 patients with both DM1 and hypertension (mean age: $50.1 \pm 6.2$ years). Aortic stiffness was measured by means of pulse wave velocity (PWV) using velocity-encoded MRI.
\end{abstract}

Brandts and van Elderen both contributed equally to this study, therefore shared first authorship is proposed.

A. Brandts $(\bowtie) \cdot$ S. G. C. van Elderen .

L. J. M. Kroft · H. J. Lamb · R. W. van der Meer .

J. J. M. Westenberg · A. de Roos

Department of Radiology, Leiden University Medical

Center, Albinusdreef 2, PO Box 9600, 2300 RC Leiden,

The Netherlands

e-mail: a.brandts@lumc.nl

J. T. Tamsma

Section of Vascular Medicine, Department of General Internal Medicine, Leiden University Medical Center, Leiden, The Netherlands

J. W. A. Smit

Department of Endocrinology, Leiden University Medical

Center, Leiden, The Netherlands
Analysis of variance (ANOVA), uni- and multivariable regression models and the Bonferroni-test for multiple testing, were used for statistical analyses. Mean aortic PWV was $5.7 \pm 1.2 \mathrm{~m} / \mathrm{s}$ in healthy volunteers, $5.9 \pm 1.2 \mathrm{~m} / \mathrm{s}$ in DM1 patients without hypertension, $7.3 \pm 1.2 \mathrm{~m} / \mathrm{s}$ in hypertensive patients and $7.3 \pm 1.3 \mathrm{~m} / \mathrm{s}$ in patients with both DM1 and hypertension. Compared to healthy control subjects, aortic PWV was significantly higher in patients with hypertension $(P<0.001)$ and in patients with both DM1 and hypertension $(P<0.001)$, whereas aortic PWV was not increased in patients having DM1 alone. Furthermore, aortic PWV was significantly higher in DM1 patients with hypertension than in patients with DM1 alone $(P=0.002)$. These findings remained after adjustment for confounding factors. Hypertension has a predominant contributive effect on aortic stiffness in DM1 patients whereas the direct diabetic effect on aortic stiffness is small.

Keywords Aortic pulse wave velocity - MRI · Type-1 diabetes mellitus · Hypertension

\section{Introduction}

Increased aortic stiffness is an important risk factor for adverse cardiovascular outcome in various disease states including diabetes mellitus (DM) [1-3]. 
Studies have demonstrated that aortic stiffness is increased in patients with particularly type-2 DM (DM2) [1, 4]. However, DM2 is commonly associated with other classical risk factors such as obesity, abnormal lipid status and hypertension that also may affect aortic stiffness [1, 5-7].

Cardiovascular risk profiles in patients with type-1 DM (DM1) usually differ from that in patients with DM2, but similar findings with respect to increased aortic stiffness have been found [3, 8-13]. An MRI study has recently shown that aortic stiffness is associated with cerebrovascular and cardiovascular end-organ damage in DM1 patients [3]. In these DM1 patient studies, the increase in aortic stiffness was relatively minor as compared to other patient groups, such as in patients with DM2 and in patients with hypertension [2, 3, 14, 15]. Also, in DM1 patients increased aortic stiffness has been measured in young DM1 patients or in DM1 patients with microvascular complications [2, 8-13]. Therefore, it is conceivable that like in DM2 patients, confounding factors may play a dominant role in aortic stiffness of DM1 patients as well.

A recent systematic review on aortic stiffness risk factors has demonstrated that age and hypertension are major and independent risk factors for aortic stiffness, while the association between DM (particularly DM2), obesity and abnormal lipid profiles with aortic stiffness were found moderate [16]. The hypothesis of our study is that hypertension also has a predominant effect on aortic stiffness in DM1 patients. To what extent DM1 itself independently adds to aortic stiffness remains to be established. Having knowledge of dominant factors affecting aortic stiffness in DM1 patients may be of value in guiding therapy, which is relevant considering the increased cardiovascular risk status in DM1 patients with increased aortic stiffness.

A widely used parameter expressing aortic stiffness is the pulse wave velocity (PWV), which is defined as the propagation speed of the pressure or flow wave front traveling along the aorta [17]. PWV is estimated by dividing the distance between anatomical locations over the aorta by the time difference between the flow waves at the two locations and is often determined by carotid-femoral PWV with means of ultrasound. However unlike ultrasound, magnetic resonance imaging (MRI) has full access to the thoracic cavity enabling quantification of direct aortic function without the need for geometrical assumptions. With MRI, PWV can be accurately and directly measured in the aorta [18].

The purpose of our study was to investigate in DM1 patients the role of hypertension and of DM1 itself on aortic PWV by using MRI.

\section{Methods}

Study population

This study was approved by the local medical ethics committee and all subjects gave informed consent to participate in the study. Consecutive patients, diagnosed with DM1 and essential hypertension, from the diabetes and hypertension outpatient clinic were eligible in our study. Healthy volunteers were also eligible and recruited by advertisement in local newspapers. All subjects were within the age range of 40-70 years and underwent MRI of the aorta between January 2005 and October 2009.

Subjects were divided into 4 subgroups based on the following criteria: group 1, healthy volunteers $(\mathrm{N}=32)$; group 2, patients with DM1 $(\mathrm{N}=20)$; group 3, patients with hypertension $(\mathrm{N}=31)$; group 4, patients with both DM1 and hypertension $(\mathrm{N}=28)$. The effect of DM1 and hypertension on aortic stiffness was investigated by comparing aortic PWV between the groups.

DM1 was defined as fasting blood glucose $\geq 7.0 \mathrm{mmol} / \mathrm{l}$ according to WHO criteria [19]. Hypertension was defined as: systolic blood pressure $>140 \mathrm{~mm} \mathrm{Hg}$ and/or diastolic blood pressure $>90$ $\mathrm{mm} \mathrm{Hg}$, on repeated physical examination before antihypertensive therapy was instituted and according to criteria of the European Society of Hypertension (ESH) [20], or blood pressure above $140 / 90 \mathrm{mmHg}$ at time of MRI. All diabetic patients were on treatment with insulin and all hypertensive patients were on treatment with antihypertensive medication. Blood pressure was measured at the time of MRI using a semi-automated sphygmomanometer (Dinamap, Critikon, Tampa, Florida, USA). Pulse pressure was defined as: systolic blood pressure-diastolic blood pressure. Furthermore, smoking status (i.e. nonsmoker or current smoker), body mass index (BMI), glycated hemoglobin (HbAlc), total cholesterol, the 
cholesterol to high-density lipoprotein (Cholesterol/ HDL) ratio, triglycerides and C-reactive protein were determined. Blood was drawn in the morning after an overnight fast within 2 weeks before MRI. The albumin excretion ratio was calculated using the microalbumin and creatinin concentrations in the urine.

Healthy volunteers underwent similar work-up as DM1 or hypertensive patients. Healthy volunteers did not comprise subjects with DM1, hypertension, cardiovascular disease, left ventricular hypertrophy as evaluated by means of electrocardiography or MRI or any systemic disease.

Exclusion criteria comprised of known history of cardiovascular disease, evidence of aortic valve stenosis or insufficiency, as evaluated by means of physical examination and velocity-encoded MRI, Marfan syndrome, aortic coarctation or any aortic disease, known history of other systemic diseases than DM1 or hypertension and general contraindications to MRI.

\section{MRI protocol}

Aortic PWV was assessed using a 1.5-T MRI scanner (NT 15 Gyroscan Intera; Philips Medical Systems, Best, the Netherlands) as previously described [18]. In short, first a longitudinal image of the aorta was acquired during a breath-hold using a segmented gradient-echo sequence. Scan parameters were: repetition time (TR) $4.0 \mathrm{~ms}$, echo time (TE) $1.05 \mathrm{~ms}$, flip angle (FA) $30^{\circ}$, field-of-view (FOV) $450 \mathrm{~mm}$, $128 \times 128$ acquisition matrix, reconstructed to $256 \times 256$, slice thickness $15 \mathrm{~mm}$ and 2 number of signal averaged (NSA) using a five-element phased array cardiac surface coil. Then, a retrospectively electrocardiographic-gated gradient-echo sequence with velocity encoding perpendicular to the aorta was applied to measure through-plane flow at two predefined levels: 1) at the level of the ascending aorta 2) at the level of the distal abdominal aorta. Scan parameters were: TR $5.0 \mathrm{~ms}$, TE $2.9 \mathrm{~ms}$, FA $20^{\circ}$, FOV $300 \mathrm{~mm}, 128 \times 115$ acquisition matrix, reconstructed to $256 \times 256$, slice thickness $8 \mathrm{~mm}$ with maximal number of phases reconstructed ensuring high (6-10 ms) temporal resolution. Maximum velocity encoding (Venc) was set to $150 \mathrm{~cm} / \mathrm{s}$ at the ascending aorta level and $100 \mathrm{~cm} / \mathrm{s}$ at the abdominal aorta level, respectively.
Image analyses

PWV was calculated using the following formula: $\Delta \mathrm{x} / \Delta \mathrm{t}(\mathrm{m} / \mathrm{s})$, where $\Delta \mathrm{x}$ describes the distance between the ascending aorta and the distal abdominal aorta and $\Delta \mathrm{t}$ describes the transit time between the arrival of the pulse wave at these respective sites. The aortic path length between the measurements sites was determined from a centerline manually positioned along the aorta using the software package MASS (Medis) [21]. Aortic velocity maps were analyzed using the in-house developed software package FLOW (Medis) [21]. The onset of the systolic wave front was automatically determined from the resulting flow graph by the intersection point of the constant diastolic flow and upslope of the systolic wave front, modeled by linear regression along the steepest part of the upslope.

Manual contour drawing in the aorta velocity maps was performed by two researchers (A.B. and S.v.E., both 3 year experience in cardiac MRI) and supervised by a senior researcher (J.J.W. 15 years experience in cardiac MRI), all unaware of the subjects' conditions.

Statistical analyses

Statistical analysis was performed using SPSS for Windows (version 17.0; SPSS, Chicago, Illinois, USA). Data are expressed as mean \pm standard deviation (SD) unless stated otherwise. Aortic PWV data were nonnormally distributed and further analyses were performed using the log-transformed PWV data. Analyses of variance (ANOVA) were used to calculate the differences between the groups concerning aortic PWV and continuous variables. The chi-square test was used to calculate the difference in dichotomous variables between groups. Pearson and Spearman correlation analyses were performed to analyze the association between aortic PWV and continuous and dichotomous variables, respectively. Pearson or Spearman correlation coefficients (r) and $P$-values are reported.

Univarible and multivariable regression models were used to correct for possible confounding factors. Age and sex were considered as standard confounding factors. Furthermore, clinical and laboratory variables that were statistically significantly different between groups (i.e. with ANOVA) and were related 
to outcome (i.e. with aortic PWV in Pearson or Spearman correlation analyses) were considered as confounding factors.

To estimate the effect of DM1, hypertension, and DM1 with hypertension on aortic PWV, healthy volunteers were used as the reference category. To estimate the additional effect of DM1 or hypertension on aortic PWV, DM1 patients with hypertension were used as the reference category. Overall $P$-values and mean \pm standard errors (SE) are reported. The Bonferroni-test was used to correct for multiple testing. A $P<0.05$ was considered statistically significant.

\section{Results}

\section{Clinical characteristics}

Table 1 describes the clinical characteristics of the study population per subgroup. Age was significantly higher in healthy volunteers and in patients with hypertension as compared to DM1 patients with and without hypertension. The group of healthy volunteers comprised of a higher male/female ratio than the other groups. Systolic blood pressure, diastolic blood pressure and pulse pressure were inherently increased in the hypertensive groups. HbA1c was inherently higher in the groups including DM1 patients. Furthermore, lipid profiles were different between groups.

Association between aortic PWV and clinical and laboratory parameters

Aortic PWV was significantly associated with age ( $\mathrm{r}=0.4, P<0.001)$, systolic blood pressure $(\mathrm{r}=0.5$, $P<0.001)$, diastolic blood pressure $(\mathrm{r}=0.3, P=$ $0.002)$, pulse pressure $(\mathrm{r}=0.4, P<0.001)$ and triglycerides $(\mathrm{r}=0.2, P=0.012)$. As pulse pressure is a resultant of systolic blood pressure minus diastolic

Table 1 Clinical characteristics of the study population per subgroup

\begin{tabular}{|c|c|c|c|c|c|}
\hline & $\begin{array}{l}\text { Healthy volunteers } \\
(\mathrm{N}=32)\end{array}$ & $\begin{array}{l}\text { DM1 } \\
(\mathrm{N}=20)\end{array}$ & $\begin{array}{l}\text { Hypertension } \\
(\mathrm{N}=31)\end{array}$ & $\begin{array}{l}\text { DM1 and hypertension } \\
(\mathrm{N}=28)\end{array}$ & $P$-value \\
\hline Age (years) & $54.5 \pm 6.8$ & $48.3 \pm 5.9$ & $59.9 \pm 7.2$ & $50.1 \pm 6.2$ & $<0.001^{*}$ \\
\hline \multicolumn{6}{|l|}{ Sex } \\
\hline Male & $24(75)$ & $8(40)$ & $10(37)$ & $15(54)$ & \multirow[t]{2}{*}{$0.016^{*}$} \\
\hline Female & $8(25)$ & $12(60)$ & $17(63)$ & $13(46)$ & \\
\hline $\begin{array}{l}\text { Systolic blood pressure } \\
(\mathrm{mmHg})\end{array}$ & $118 \pm 11$ & $120 \pm 10$ & $165 \pm 18$ & $141 \pm 19$ & $<0.001^{*}$ \\
\hline $\begin{array}{l}\text { Diastolic blood pressure } \\
(\mathrm{mmHg})\end{array}$ & $76 \pm 9$ & $69 \pm 7$ & $96 \pm 13$ & $76 \pm 10$ & $<0.001^{*}$ \\
\hline Pulse Pressure (mmHg) & $42 \pm 12$ & $51 \pm 9$ & $69 \pm 19$ & $64 \pm 15$ & $<0.001^{*}$ \\
\hline \multicolumn{6}{|l|}{ Smoking } \\
\hline No & $28(87)$ & $18(90)$ & $22(81)$ & $23(22)$ & \multirow[t]{2}{*}{0.830} \\
\hline Yes & $4(13)$ & $2(10)$ & $5(19)$ & $5(18)$ & \\
\hline Body mass index $(\mathrm{kg} / \mathrm{m} 2)$ & $26.9 \pm 3.0$ & $24.4 \pm 2.1$ & $26.0 \pm 4.7$ & $26.5 \pm 3.4$ & 0.087 \\
\hline HbA1c $(\%)$ & $5.4 \pm 0.2$ & $7.0 \pm 1.0$ & $5.2 \pm 0.3$ & $7.8 \pm 1.0$ & $<0.001^{*}$ \\
\hline Cholesterol (mmol/l) & $5.3 \pm 0.9$ & $4.5 \pm 0.7$ & $5.6 \pm 1.0$ & $4.9 \pm 1.0$ & $0.001 *$ \\
\hline $\begin{array}{l}\text { Cholesterol/HDL ratio } \\
(\mathrm{mmol} / \mathrm{l})\end{array}$ & $3.7 \pm 1.0$ & $2.8 \pm 0.6$ & $3.7 \pm 1.1$ & $3.2 \pm 1.0$ & $0.003^{*}$ \\
\hline Triglycerides (mmol/l) & $1.1 \pm 0.5$ & $0.9 \pm 0.3$ & $1.4 \pm 0.4$ & $1.6 \pm 1.0$ & $<0.001 *$ \\
\hline C-reactive protein & $1.9 \pm 1.8$ & $1.6 \pm 1.5$ & $2.4 \pm 2.7$ & $2.7 \pm 3.7$ & 0.466 \\
\hline Microalbuminuria & $1.5 \pm 2.1$ & $1.0 \pm 1.5$ & $2.3 \pm 4.4$ & $1.8 \pm 3.2$ & 0.567 \\
\hline
\end{tabular}

Values are mean \pm SD or data are numbers of patients and numbers in parentheses are percentages

$D M 1$ Type-1 Diabetes mellitus patients, $H b A 1 c$ Glycated hemoglobin, $H D L$ high density lipoprotein

$* P$-value $<0.05$ 
Table 2 Difference in aortic PWV between subgroups before and after correction for confounding factors

\begin{tabular}{llcc}
\hline Reference category & $\begin{array}{l}\text { Uncorrected } \\
\text { model } \\
P \text {-value }\end{array}$ & $\begin{array}{l}\text { Model corrected } \\
\text { for age and sex } \\
P \text {-value }\end{array}$ & $\begin{array}{c}\text { Model corrected for age, sex, } \\
\text { pulse pressure and triglycerides } \\
P \text {-value }\end{array}$ \\
\hline $\begin{array}{l}\text { a. Healthy volunteers } \\
\text { DM1 patients }\end{array}$ & 0.528 & 0.058 & 0.198 \\
Hypertensive patients & $<0.001 *$ & $<0.001^{*}$ & $<0.001^{*}$ \\
DM1 patients with hypertension & $<0.001^{*}$ & $<0.001^{*}$ & $<0.001^{*}$ \\
b. DM1 patients with hypertension & & & 0.668 \\
Hypertensive patients & 0.665 & 0.668 & 0.228 \\
DM1 patients & $0.002 *$ & $0.030^{*}$ & \\
\hline
\end{tabular}

DM1: type-1 diabetes mellitus patients

* $P$-value $<0.05$

a. Healthy volunteers serve as the reference category; b. DM1 patients with hypertension serve as the reference category

blood pressure, pulse pressure was considered as a confounding factor, whereas systolic and diastolic blood pressure were not. Sex, smoking status, BMI, HbA1c, lipid status, C-reactive protein and microalbuminuria did not correlate with aortic PWV.

Independent and combined effect of DM1 and hypertension on aortic PWV

Mean aortic PWV was $5.7 \pm 1.2 \mathrm{~m} / \mathrm{s}$ in healthy subjects, $5.9 \pm 1.2 \mathrm{~m} / \mathrm{s}$ in DM1 patients, $7.3 \pm 1.2$ $\mathrm{m} / \mathrm{s}$ in hypertensive patients without diabetes and $7.3 \pm 1.3 \mathrm{~m} / \mathrm{s}$ in DM1 patients with hypertension. Table 2 describes the uni- and multivariable regression models for assessment of the independent and combined effect of DM1 and hypertension on aortic stiffness, before and after correction for confounding factors.

Without correction for confounding factors, aortic PWV was statistically significantly higher in patients with hypertension $(P<0.001)$ and in patients with both DM1 and hypertension $(P<0.001)$, but not in patients having only DM1 $(P=0.528)$ as compared to healthy volunteers (Table 2a). Furthermore, aortic PWV was statistically significantly higher in DM1 patients with hypertension as compared to DM1 patients $(P=0.002)$, whereas aortic PWV was not statistically significantly different between DM1 patients with hypertension and hypertensive patients (Table $2 b$ ).

After correction for standard confounding factors age and sex, the differences in aortic PWV remained comparable between groups (Table 2). Mean aortic
PWV was $5.4 \pm 1.0 \mathrm{~m} / \mathrm{s}$ in healthy subjects, $6.3 \pm$ $1.1 \mathrm{~m} / \mathrm{s}$ in DM1 patients, $7.2 \pm 1.0 \mathrm{~m} / \mathrm{s}$ in hypertensive patients and $7.3 \pm 1.0 \mathrm{~m} / \mathrm{s}$ in DM1 patients with hypertension. Figure 1 shows the difference between the groups regarding aortic PWV corrected for age and sex; having DM1 alone does not statistically significantly affect aortic PWV as compared to healthy volunteers, although a slight trend for increased aortic PWV in DM1 patients as compared to healthy volunteers can be observed. Conversely, hypertension has major effect in increasing aortic PWV (Fig. 1).

After correction for age, gender, pulse pressure and triglycerides mean aortic PWV was $5.6 \pm 1.1 \mathrm{~m} / \mathrm{s}$ in healthy subjects, $6.4 \pm 1.1 \mathrm{~m} / \mathrm{s}$ in DM1 patients, $7.1 \pm 1.0 \mathrm{~m} / \mathrm{s}$ in hypertensive patients without diabetes and $7.2 \pm 1.0 \mathrm{~m} / \mathrm{s}$ in DM1 patients with hypertension. Additionally correcting for pulse pressure and triglycerides as confounding factors, had effect on the difference in aortic PWV between DM1 patients with hypertension and patients having only DM1, which was no longer statistically significantly different from each other (Table 2b). This was expected because pulse pressure and triglycerides are inherently increased in subgroups with DM1 and hypertension; by correcting for these confounders group outcomes were equalized.

\section{Discussion}

We investigated the independent and combined effect of DM1 and hypertension on aortic stiffness by 


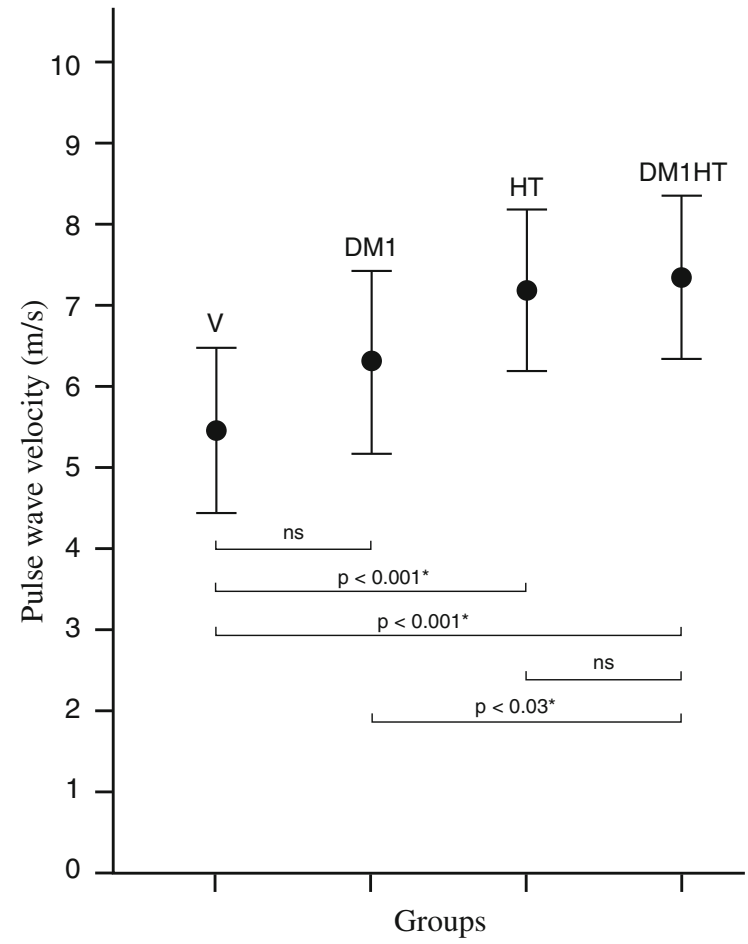

Fig. 1 Difference in aortic PWV between subgroups corrected for age and sex. $V$ Healthy volunteers, $D M 1$ type- 1 diabetes mellitus patients, $H T$ hypertension patients, DM $1 H T$ type-1 diabetes mellitus patients with hypertension. Means \pm SE per subgroup are given and $P$-values between subgroups are presented below. ${ }^{*} P<0.05$. ns: non-significant

comparing four subgroups including DM1 patients with and without hypertension, hypertensive patients and healthy volunteers by using MRI. The main finding was that the independent effect of DM1 on aortic PWV was minor; aortic PWV was not significantly different between healthy volunteers and DM1 patients. In addition, no differences were found in aortic PWV between DM1 patients with hypertension and hypertensive patients that remained after correction for confounding factors age, gender, pulse pressure and triglycerides. Secondly, the independent effect of hypertension on aortic PWV was major; aortic PWV was significantly higher in hypertensive patients than in healthy volunteers. In addition, the combination of DM1 and hypertension resulted in increased aortic stiffness, and was significantly higher than in patients having DM1 alone, that remained after correction for age and sex.

Previous studies have demonstrated increased aortic stiffness in DM1 patients with microvascular complications including microalbuminuria or hypertension as compared to healthy volunteers [2, 8-13]. Age and hypertension are well-established risk factors of aortic stiffness and hypertension is often present in DM1. It is therefore conceivable that multiple factors may contribute to aortic stiffness in DM1 patients. We investigated the effect of DM1 itself on aortic PWV by evaluating a relatively wellcontrolled, uncomplicated DM1 patient group with an age range between 40 and 70 years old. In DM1 patients, aortic stiffness was not significantly different from healthy volunteers although a trend towards increased aortic stiffness was observed after correction for age and sex. When comparing subgroups, triglycerides and pulse pressure were inherently increased in patients with hypertension. Therefore, after additional correction for triglycerides and pulse pressure, differences between DM1 patients with hypertension and patients having DM1 alone became non-significant, that was explained by equalizing subgroups.

Hypertension is a well-known major and independent risk factor for aortic stiffness [16, 22], that was also found in our study. Investigating the hypertensive contribution on aortic stiffness in patients with DM1 is relevant for cardiovascular risk assessment, as DM1 is often associated with hypertension, especially in the elderly [2, 16]. Age and blood pressure have consistently been shown to be independently associated with PWV [16]. The impact of hypertension on aortic stiffening may be twofold: 1 . mechanistic stretching of the arterial wall may result in aortic stiffening; 2. structural changes of the arterial wall due to cyclic stress, resulting in stress fracturing of elastin and consequent stiffening $[16,23]$. In contrast to the predominant effect of hypertension on aortic stiffening, only weak correlations have been shown with diabetes, accounting for a mean of $5 \%$ of the variation in PWV [16]. It is generally believed that increased aortic stiffness plays an important role in the pathway linking various diseases, including DM1 with increased cardiovascular risk factors $[1,2]$. We have now demonstrated that aortic stiffness in DM1 patients mainly depends on having additional hypertension, and not on DM1 alone. Thus, identification of hypertension in patients with DM1 is of importance for risk stratification and may be used for stratifying therapy as to improve cardiovascular outcome. 
Some study limitations are addressed. This study has a cross-sectional design. Therefore, direct causative mechanisms of the effect of DM1 itself and of hypertension cannot be determined. Follow-up studies are required for further evaluation of the role of DM1 and hypertension on aortic stiffness. From our study design with four subgroups it was difficult to exactly age- and gender match all patients and volunteers. Therefore, multivariable regression models were used to account for possible confounding factors, including age. After correction for age and sex, the differences in aortic PWV remained comparable between subgroups.

In conclusion, hypertension has a predominant contributive effect on aortic stiffness in DM1 patients whereas the direct diabetic effect on aortic stiffness is small. As aortic stiffness and DM1 are highly associated with adverse cardiovascular outcome, identifying hypertension in DM1 patients seems highly relevant for risk stratification.

Acknowledgements This research was performed within the framework of the Center for Translational Molecular Medicine (CTMM; www.ctmm.nl), project PREDICCt (grant 01C-104), and supported by the Netherlands Heart Foundation (NHS2003B136 and NHS2007B81 to P.C.N. Rensen), Dutch Diabetes Research Foundation and Dutch Kidney Foundation.

\section{Conflicts of interest None}

Open Access This article is distributed under the terms of the Creative Commons Attribution Noncommercial License which permits any noncommercial use, distribution, and reproduction in any medium, provided the original author(s) and source are credited.

\section{References}

1. Cruickshank K, Riste L, Anderson SG, Wright JS, Dunn G, Gosling RG (2002) Aortic pulse-wave velocity and its relationship to mortality in diabetes and glucose intolerance: an integrated index of vascular function? Circulation 106:2085-2090

2. Stehouwer CD, Henry RM, Ferreira I (2008) Arterial stiffness in diabetes and the metabolic syndrome: a pathway to cardiovascular disease. Diabetologia 51:527-539

3. van Elderen SG, Brandts A, Westenberg JJ, van der Grond J, Tamsma JT, van Buchem MA, Romijn JA, Kroft LJ, Smit JW, de Roos A (2009) Aortic stiffness is associated with cardiac function and cerebral small vessel disease in patients with type 1 diabetes mellitus: assessment by magnetic resonance imaging. Eur Radiol 20:1132-1138

4. Henry RM, Kostense PJ, Spijkerman AM, Dekker JM, Nijpels G, Heine RJ, Kamp O, Westerhof N, Bouter LM, Stehouwer CD (2003) Arterial stiffness increases with deteriorating glucose tolerance status: the Hoorn Study. Circulation 107:2089-2095

5. Sutton-Tyrrell K, Newman A, Simonsick EM, Havlik R, Pahor M, Lakatta E, Spurgeon H, Vaitkevicius P (2001) Aortic stiffness is associated with visceral adiposity in older adults enrolled in the study of health, aging, and body composition. Hypertension 38:429-433

6. Zebekakis PE, Nawrot T, Thijs L, Balkestein EJ, van der Heijden-Spek J, Van Bortel LM, Struijker-Boudier HA, Safar ME, Staessen JA (2005) Obesity is associated with increased arterial stiffness from adolescence until old age. J Hypertens 23:1839-1846

7. Asmar R, Benetos A, London G, Hugue C, Weiss Y, Topouchian J, Laloux B, Safar M (1995) Aortic distensibility in normotensive, untreated and treated hypertensive patients. Blood Press 4:48-54

8. Giannattasio C, Failla M, Piperno A, Grappiolo A, Gamba P, Paleari F, Mancia G (1999) Early impairment of large artery structure and function in type I diabetes mellitus. Diabetologia 42:987-994

9. Brooks B, Molyneaux L, Yue DK (1999) Augmentation of central arterial pressure in type 1 diabetes. Diabet Care 22:1722-1727

10. Parikh A, Sochett EB, McCrindle BW, Dipchand A, Daneman A, Daneman D (2000) Carotid artery distensibility and cardiac function in adolescents with type 1 diabetes. J Pediatr 137:465-469

11. Giannattasio C, Failla M, Grappiolo A, Gamba PL, Paleari F, Mancia G (2001) Progression of large artery structural and functional alterations in Type I diabetes. Diabetologia 44:203-208

12. Haller MJ, Samyn M, Nichols WW, Brusko T, Wasserfall C, Schwartz RF, Atkinson M, Shuster JJ, Pierce GL, Silverstein JH (2004) Radial artery tonometry demonstrates arterial stiffness in children with type 1 diabetes. Diabet Care 27:2911-2917

13. Lacy PS, O’Brien DG, Stanley AG, Dewar MM, Swales PP, Williams B (2004) Increased pulse wave velocity is not associated with elevated augmentation index in patients with diabetes. J Hypertens 22:1937-1944

14. van der Meer RW, Diamant M, Westenberg JJ, Doornbos J, Bax JJ, de Roos A, Lamb HJ (2007) Magnetic resonance assessment of aortic pulse wave velocity, aortic distensibility, and cardiac function in uncomplicated type 2 diabetes mellitus. J Cardiovasc Magn Reson 9:645-651

15. Brandts A, van Elderen SG, Westenberg JJ, van der Grond J, van Buchem MA, Huisman MV, Kroft LJ, Tamsma JT, de Roos A (2009) Association of aortic arch pulse wave velocity with left ventricular mass and lacunar brain infarcts in hypertensive patients: assessment with MR imaging. Radiology 253:681-688

16. Cecelja M, Chowienczyk P (2009) Dissociation of aortic pulse wave velocity with risk factors for cardiovascular disease other than hypertension: a systematic review. Hypertension 54:1328-1336

17. Laurent S, Cockcroft J, Van Bortel L, Boutouyrie P, Giannattasio C, Hayoz D, Pannier B, Vlachopoulos C, Wilkinson I, Struijker-Boudier H (2006) Expert consensus document on arterial stiffness: methodological issues and clinical applications. Eur Heart J 27:2588-2605 
18. Grotenhuis HB, Westenberg JJ, Steendijk P, van der Geest RJ, Ottenkamp J, Bax JJ, Jukema JW, de Roos A (2009) Validation and reproducibility of aortic pulse wave velocity as assessed with velocity-encoded MRI. J Magn Reson Imaging 30:521-526

19. Alberti KG, Zimmet PZ (1998) Definition, diagnosis and classification of diabetes mellitus and its complications. Part 1: diagnosis and classification of diabetes mellitus provisional report of a WHO consultation. Diabet Med 15:539-553

20. Mancia G, De Backer G, Dominiczak A, Cifkova R, Fagard R, Germano G, Grassi G, Heagerty AM, Kjeldsen SE, Laurent S, Narkiewicz K, Ruilope L, Rynkiewicz A, Schmieder RE, Boudier HA, Zanchetti A (2007)
Guidelines for the management of arterial hypertension: the task force for the management of arterial hypertension of the european society of hypertension (ESH) and of the european society of cardiology (ESC). J Hypertens 25:1105-1187

21. van der Geest RJ, De Roos A, Van der Wall EE, Reiber JH (1997) Quantitative analysis of cardiovascular MR images. Int J Card Imaging 13:247-258

22. Safar ME, Levy BI, Struijker-Boudier H (2003) Current perspectives on arterial stiffness and pulse pressure in hypertension and cardiovascular diseases. Circulation 107:2864-2869

23. Cecelja M, Chowienczyk P (2010) Arterial stiffening: cause and prevention. Hypertension 56:29-30 